Arq. Bras. Med. Vet. Zootec., v.60, n.2, p.315-321, 2008

\title{
Obstrução nasal por granuloma fúngico em eqüino: relato de caso
}

[Nasal obstruction caused by fungal granuloma in a horse: case report]

\author{
A.L.V. Zoppa, R. Crispim, I.L. Sinhorini, N.R. Benites, L.C.L.C. Silva, R.Y.A. Baccarin \\ Faculdade de Medicina Veterinária e Zootecnia - USP \\ Av. Prof. Orlando Marques de Paiva, 87 \\ 05508-000 - São Paulo, SP
}

\begin{abstract}
RESUMO
Um eqüino de nove anos de idade apresentou ausência de ar expirado e secreção serossanguinolenta na narina direita, associado a ruído respiratório. Os exames endoscópico e radiológico mostraram uma formação de aproximadamente seis centímetros de diâmetro recoberta por mucosa amarelada, que obstruía a cavidade nasal direita e insinuava-se para a cavidade nasal esquerda. Tal massa foi ressecada por meio de sinusotomia frontal direita. $\mathrm{O}$ exame histológico e a cultura revelaram lesão granulomatosa causada por fungos. O tratamento pósoperatório compreendeu associação de antibiótico e antiinflamatório, assim como de lavagens com água destilada e chá de camomila.
\end{abstract}

Palavras-chave: eqüino, aspergillus sp., criptococcus sp., obstrução nasal, granuloma fúngico

\begin{abstract}
A 9-year-old horse presented serosanguineous nasal discharge, absence of breath out through the right nostril, and respiratory noise. Endoscopic and radiographic exams revealed a six centimeter diameter mass, covered by yellowish mucosa, which was obstructing the entire right nasal cavity and part of the left one. The mass was excised through a right frontal sinusotomy. The microscopic exam and the culture revealed a fungic granulomatous rhinitis. Antibiotic and anti-inflammatory drugs were postoperatively administered; moreover, camomile tea and distilled water were flushed in a drain placed above the bone flap.
\end{abstract}

Keywords: horse, aspergillus sp., criptococcus sp., nasal obstruction, fungal granuloma

\section{INTRODUÇ̃̃O}

As infecções micóticas são incomuns no trato respiratório superior de eqüinos. Podem ser causadas por Aspergillus sp., Rhinosporidiun sp., Conidiobollus sp., Pseudallescheria sp., Mucoraceous sp., Coccidioides immitis, Criptococcus sp. e outras espécies de zigomicetos (Londero et al., 1977; Korenek et al., 1994; Davis et al., 2000). Dentre estes agentes, o Aspergillus sp. é o principal causador das rinites micóticas (McGorum et al., 1992; Tremaine e Dixon, 2001) e micoses de bolsa gutural (Ragle, 2003).

A aspergilose nasal descrita como rinite primária (Greet, 1981) ou em associação com sinusites (Gibbs e Lane, 1987) é considerada rara. Guida et al. (2005) relataram presença de Aspergillus

Recebido em 5 de abril de 2006

Aceito em 13 de dezembro de 2007

E-mail: alzoppa@usp.br fumigatus em 11,5\% de 226 amostras de secreção nasal de eqüinos saudáveis, caracterizando-o como um agente oportunista e cosmopolita. Sanches (1998) isolou Aspergillus sp. em 53\%, 62\%, 82\% e $14 \%$ das amostras de lavado traqueobrônquico obtidas, respectivamente, de eqüinos hígidos, eqüinos portadores de alterações morfofuncionais, infecções bacterianas e infecções virais do trato respiratório superior.

Granulomas causados por Conidiobolus coronata, Conidiobolus lampranges, Criptococcus neoformans, Coccidioides immitis, Rhinosporidium seeberi, e Pseudasllescheria boydii foram observados nos seios frontal e maxilar, palato, nasofaringe e conchas nasais de eqüinos (Scott, 1974; Roberts et al., 1981; Brearley et al., 1986; Humber et al., 1989; Freeman et al., 1990; Zamos et al., 1996; Grecco et al., 2003; Reis et al., 2006). 
Apesar de a criptococose ter distribuição mundial e acometer pessoas e animais, ela é incomum em eqüinos (Lenard et al., 2007). Acredita-se que a infecção por Criptococcus neoformans em cavalos seja secundária a lesões decorrentes da passagem de sonda nasogástrica, infecções virais ou bacterianas do trato respiratório superior, ou seqüela da hemorragia pulmonar induzida por exercício (Begg et al., 2004). Ocorre mais comumente em animais com queda na imunidade local ou sistêmica, ou que são expostos a fatores como debilidade, desnutrição, ou uso prolongado de corticosteróides (Kommers et al., 2005).y

O eqüino acometido por infecção fúngica do trato respiratório superior pode manifestar dispnéia, intolerância ao exercício, secreção nasal uni ou bilateral, aumento de volume facial, diminuição ou até obstrução total do fluxo de ar pelas narinas, aumento de volume dos linfonodos submandibulares, disfagia, fístulas, odor fétido e ruídos respiratórios, dependendo do agente, localização e cronicidade da infecção. A secreção nasal pode ser serosa, purulenta, mucopurulenta ou serossanguinolenta. Esta última indica neoplasia ou lesão fúngica granulomatosa (Greet, 1981; Brearley et al., 1986; Tremaine e Dixon, 2001; Ragle, 2003).

O diagnóstico é feito por meio do histórico, sinais clínicos, exame físico, exame citológico e cultura da secreção nasal. O exame endoscópico é utilizado para determinar a origem da secreção nasal e a integridade da cavidade nasal. Neste exame, os granulomas fúngicos geralmente são identificados, apresentando-se firmes, lobulados ou não e recobertos por mucosa, sendo que partes dessa mucosa podem estar ulceradas. Placas fúngicas também podem ser observadas na cavidade nasal (Greet, 1981; Brearley et al., 1986; Tremaine e Dixon, 2001).

O estudo radiográfico tem grande valor para o diagnóstico de afecções dos seios paranasais e é utilizado para determinar a localização e a extensão da enfermidade. Contudo, as infecções fúngicas geralmente apresentam alterações inespecíficas, tais como opacificação difusa, pouco acúmulo de líquido nos seios paranasais, não evidenciando o local das placas fúngicas. Aproximadamente 19\% das alterações radiográficas nos seios paranasais correspondem à sinusite primária, sendo que 9,3\% dessas sinusites são causadas por infecção fúngica (Gibbs e Lane, 1987). No exame radiográfico, os granulomas fúngicos podem apresentar-se com paredes lisas, aumento de densidade de tecidos moles, localizados na cavidade nasal ou seios paranasais (Tremaine e Dixon, 2001). Outros métodos diagnósticos incluem sinocentese e sinoscopia (Brearley et al., 1986).

O diagnóstico definitivo é obtido por meio de biópsia representativa com auxílio de endoscopia ou excisão cirúrgica. A identificação do organismo é possível utilizando-se cultura fúngica (Freeman, 1991).

O tratamento das afecções fúngicas no trato respiratório superior geralmente é difícil e de prognóstico reservado, pois freqüentemente é prolongado, e os agentes antifúngicos são caros (Lenard et al., 2007), além de serem, em sua maioria, tóxicos (Chandna et al., 1992). Anfoterecina B, miconazol, natamicina, flucitosina e cetoconazol podem ser eficientes no tratamento de rinite fúngica.

As lesões fúngicas granulomatosas requerem remoção cirúrgica e estabelecimento de drenagem adequada. Recomenda-se a irrigação intensa dos seios com solução estéril até a cicatrização total do local de trepanação (Ainsworth e Biller, 2000). O acesso cirúrgico dos seios paranasais é por trepanação ou sinusotomia por elevação de retalho. Os cavalos que têm boa evolução após a retirada de granuloma fúngico geralmente desenvolvem lesões contralaterais semelhantes (Freeman, 1991).

Anfoterecina B intravenosa por pelo menos um mês foi usada com sucesso no tratamento de granulomas micóticos em eqüinos; já os antifúngicos tópicos parecem ter pouco efeito no tratamento de grandes granulomas fúngicos, mas podem ser aplicados após a retirada cirúrgica (Freeman, 1991). Componentes da planta camomila (Matricaria recutita, Chamomilla recutita, Matricaria chamomilla) tais como chamazulene, $\alpha$-bisabolol, flavonóides e umbelliferone apresentam propriedades antibacterianas e antifúngicas, além de atividades antioxidante, antiplaquetária e antiinflamatória (Gardiner, 1999; McKay e Blumberg, 2006).

Este relato registra os achados clínicos, exames auxiliares diagnósticos e tratamento de um eqüino acometido por infecção fúngica nasal.

\section{RELATO DO CASO}

Em hospital veterinário, foi atendido um eqüino, macho, de nove anos de idade, da raça American Trotter, pesando $422 \mathrm{~kg}$, cujo histórico relatava queda no desempenho atlético, secreção nasal unilateral direita e ruído respiratório, há 30 dias. 
Durante o exame físico, observou-se quantidade moderada de secreção nasal mucopurulenta e ausência de fluxo de ar pela narina direita, bem como aumento do linfonodo submandibular direito.

Ao exame endoscópico, verificou-se a presença de uma massa na cavidade nasal direita, obstruindo-a completamente e impossibilitando a progressão do endoscópio e inspeção do osso etmóide (Fig. 1A) $\mathrm{Na}$ cavidade nasal esquerda, observou-se projeção da massa sob o septo nasal, proveniente da cavidade direita, causando obstrução parcial (Fig. 1B). Em ambas as narinas, a formação apresentavase recoberta por mucosa amarelada.

O exame radiográfico revelou uma única estrutura irregular, arredondada, com aproximadamente seis centímetros de diâmetro e aumento de densidade radiográfica em tecidos moles, sendo que $80 \%$ de seu volume ocupava a cavidade nasal, seio frontal e etmóide direito, e seu limite caudal era o último dente molar (Fig. 2).

Com o diagnóstico sugestivo de hematoma etmoidal, o animal foi encaminhado para tratamento cirúrgico. $\mathrm{O}$ acesso à formação deu-se por sinusotomia frontal direita com incisão de pele e periósteo de aproximadamente seis centímetros de raio. Foram rebatidos pele e periósteo, e o osso frontal foi fraturado em região previamente fragilizada por perfurações feitas com broca na mesma linha da incisão de pele.

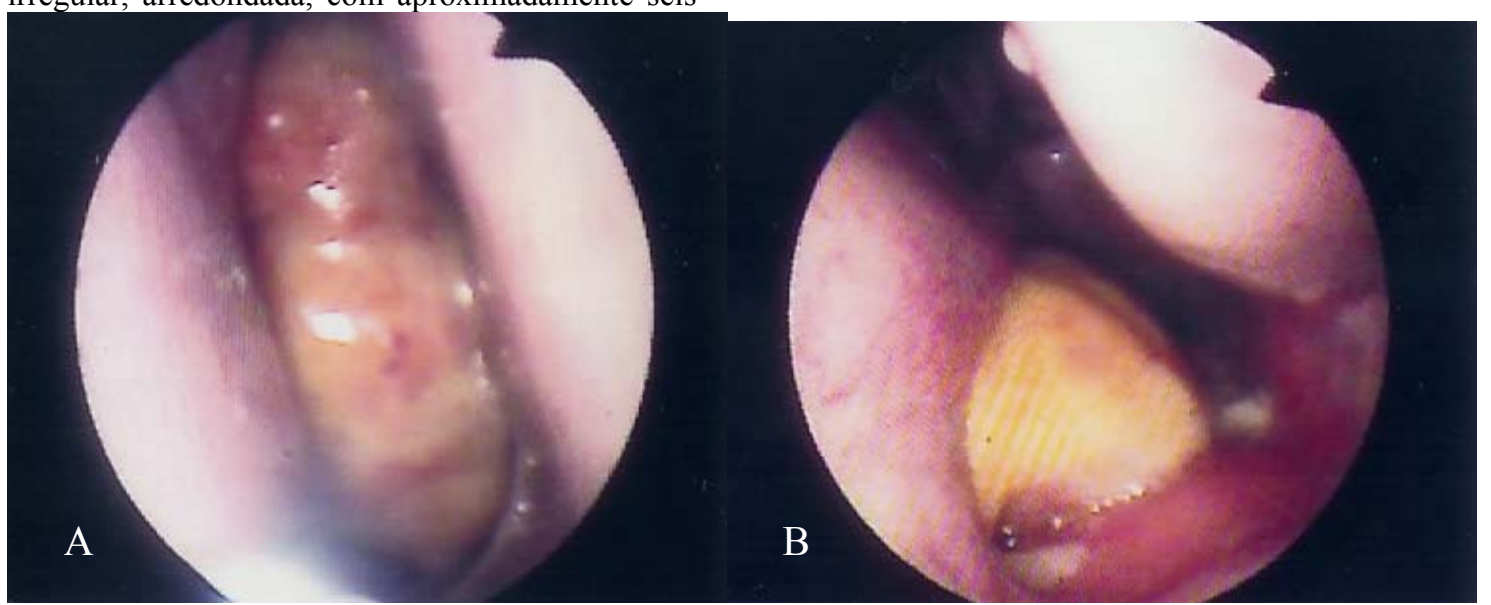

Figura 1. A) imagem endoscópica do granuloma em eqüino, obstruindo totalmente a cavidade nasal direita; B) imagem endoscópica da cavidade nasal esquerda em eqüino, apresentando projeção do granuloma sob o septo nasal, obstruindo-a parcialmente.

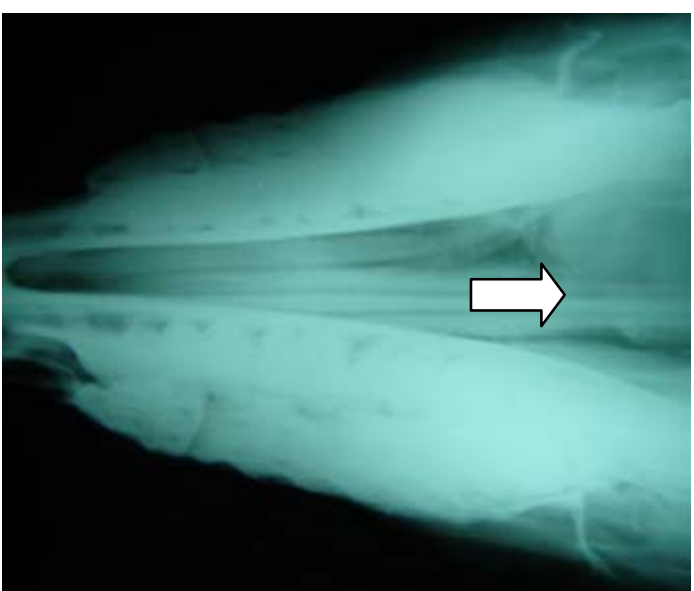

Figura 2. Imagem radiográfica de crânio na incidência dorsoventral evidenciando a localização do granuloma fúngico (seta) em eqüino.
Foi realizada a ressecção da massa que macroscopicamente apresentava-se amarelada e firme. Ocupava o seio frontal direito, toda a região do etmóide direito e parte do seio frontal esquerdo e obstruía a cavidade nasal direita, insinuando-se para a cavidade nasal esquerda. Caudal ao acesso cirúrgico, foi feita uma incisão de pele de aproximadamente dois centímetros e posterior trepanação para fixação de um dreno de Pezze no interior do seio frontal, que permitiria a irrigação do local no período pós-operatório.

Durante o período pós-operatório, foram feitos exames físicos duas vezes ao dia e realizados exames endoscópicos semanais para a avaliação do processo cicatricial. Amostras sangüíneas foram colhidas semanalmente para realização de hemograma e análise bioquímica. 
O tratamento pós-operatório iniciou-se com associação de penicilinas ${ }^{1} \quad(6.000 .000 \mathrm{UI}$ de benzatina, $1.500 .000 \mathrm{UI}$ de procaína e $1.500 .000 \mathrm{UI}$ de potássica), 40.000UI/kg por via intramuscular (IM) duas vezes ao dia durante sete dias e gentamicina $^{2}$ na dose de $6,6 \mathrm{mg} / \mathrm{kg}$ por via intravenosa (IV) uma vez ao dia durante sete dias. Como antiinflamatório, foram utilizados $2,2 \mathrm{mg} / \mathrm{kg}$ de fenilbutazona ${ }^{3}$ IV uma vez ao dia durante 10 dias.

A lavagem dos seios paranasais e da cavidade nasal direitos foi realizada com solução mucolítica contendo $12,5 \mathrm{mg}$ de lauril dietil éter sulfato de sódio ${ }^{4}$ diluído em um litro de solução fisiológica, seguida de dois litros de água destilada sob pressão.

Após 10 dias do término do tratamento com penicilina, o animal apresentou secreção nasal mucopurulenta. Baseado em cultura e antibiograma, que revelaram o crescimento de Pseudomonas aeruginosa, Serratia sp. e Streptococcus sp. não hemolítico, foi iniciado o tratamento com enrofloxacina $^{5}$ na dose de $2,5 \mathrm{mg} / \mathrm{kg}$ IM com intervalo de 12 horas entre as aplicações por um período de três dias.

O material colhido durante a cirurgia foi enviado ao laboratório de patologia animal para exame histológico utilizando-se os métodos de coloração com hematoxilina-eosina e método específico para revelação de fungos segundo Grocott. A avaliação microscópica revelou rinite fúngica granulomatosa, sendo que as colorações utilizadas evidenciaram uma cápsula circundando os microrganismos, interpretados como Criptococcus sp. (Fig. 3A e 3B).

Três semanas após a cirurgia, durante exame endoscópico de controle, foram observadas duas placas com características fúngicas, de aproximadamente dois centímetros de comprimento na região anteriormente ocupada pela formação. Com o animal sedado e em estação, foi introduzida uma pinça de artroscopia através do orifício onde se encontrava fixado o dreno de Pezze. As placas foram retiradas de forma assistida pela endoscopia nasal (Fig. 4). O dreno foi fixado novamente para a continuidade das lavagens. Um fragmento foi

${ }^{1}$ Pentabiótico ${ }^{\circledR}$ - Fort Dodge Saúde Animal - São Paulo, Brasil.

${ }^{2}$ Gentatec $^{\circledR}$ - Chemitec Agro-veterinária Ltda. - São Paulo, Brasil.

${ }^{3}$ Equipalazone ${ }^{\circledR}$ - Marcolab - Duque de Caxias, Brasil

${ }^{4}$ Tergenvet $^{\circledR}$ - Univet S/A Ind. Veterinária - São Paulo, Brasil. ${ }^{5}$ Flotril $^{\circledR}$ - Schering-Plough_Produtos farmacêuticos Ltda. São Paulo, Brasil. retirado do bordo ulcerado onde se localizavam as placas fúngicas, enviado para cultura no laboratório de bacteriologia e micologia. A amostra foi macerada em solução salina e semeada em ágar sabouraud com cloranfenicol. A leitura, realizada em sete dias, evidenciou crescimento de Aspergillus sp.

Após a retirada das placas, iniciaram-se lavagens da região somente com infusão de chá de camomila $(5 \mathrm{~g} / \mathrm{l})$. Duas semanas após a retirada dessas placas, durante exame endoscópico de controle, foram observadas novas placas fúngicas, que foram retiradas, desta vez com pinça de apreensão passada pelo canal de trabalho do fibroscópio. As lavagens da região foram realizadas até a cicatrização completa da mucosa, o que ocorreu sete dias após a última retirada das placas fúngicas.

Após seis meses do tratamento, segundo contato telefônico com o proprietário, o eqüino não apresentou alterações respiratórias, tendo retornado à atividade esportiva sem perda de desempenho atlético.

\section{DISCUSSÃO E CONCLUSÕES}

A presença de secreção nasal mucopurulenta unilateral em eqüinos é freqüentemente associada à sinusite bacteriana e ao hematoma etmoidal, mas as infecções fúngicas devem ser consideradas como diagnóstico diferencial.

Como descrito por Gibbs e Lane (1987), lesões fúngicas apresentam alterações radiográficas inespecíficas, não sendo possível identificar o local de formação da placa fúngica. Quando a formação é granulomatosa, o exame radiográfico somente delimita a extensão da lesão, não possibilitando um diagnóstico preciso. O exame endoscópico é essencial, permitindo observação do aspecto da lesão e a relação com estruturas adjacentes (Greet, 1981).

No caso clínico relatado, as alterações encontradas nos exames radiográfico e endoscópico, quanto à localização e extensão da lesão, sugeriram erroneamente hematoma etmoidal, indicando a necessidade de ressecção cirúrgica. Apesar do diagnóstico errôneo, a indicação cirúrgica foi procedente, pois o grau de obstrução das vias aéreas comprometeria não somente o desempenho atlético do animal, mas também sua sobrevida. 


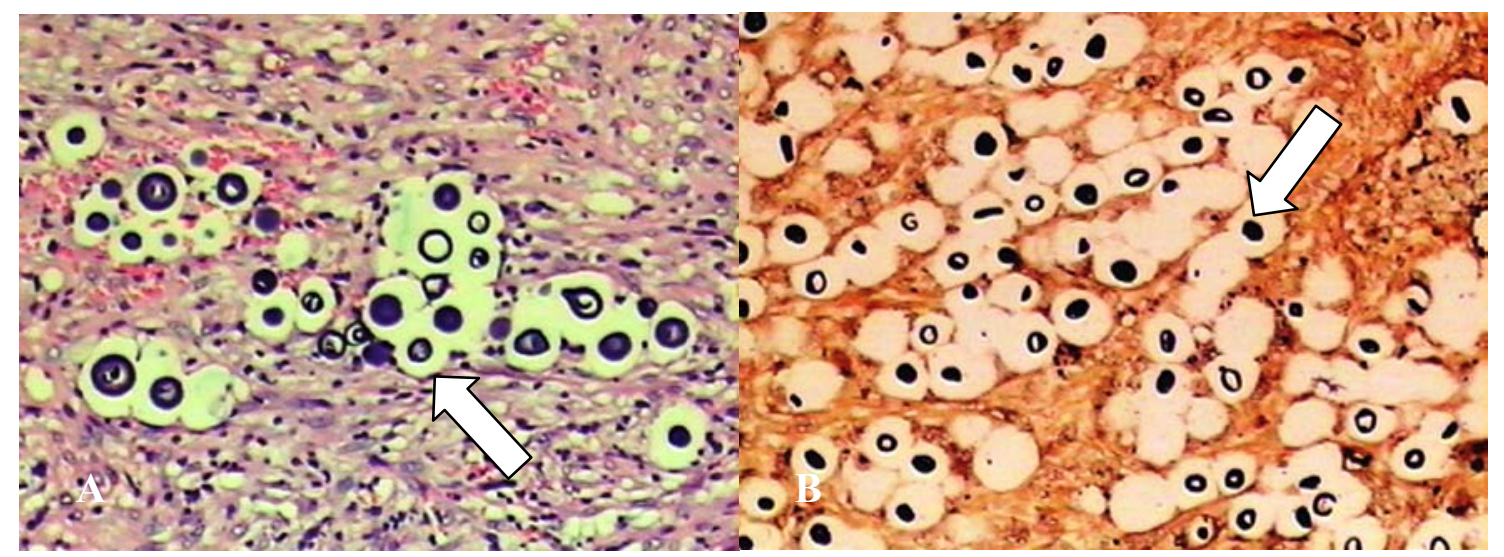

Figura 3. A) corte histológico corado pelo método de hematoxilina-eosina, revelando lesão granulomatosa causada por esporos fúngicos em eqüino -, aumento de 10x (seta); B) corte histológico corado pelo método de Grocott, revelando lesão granulomatosa em eqüino, causada por esporos de Cryptococcus sp., aumento de 10x (seta).

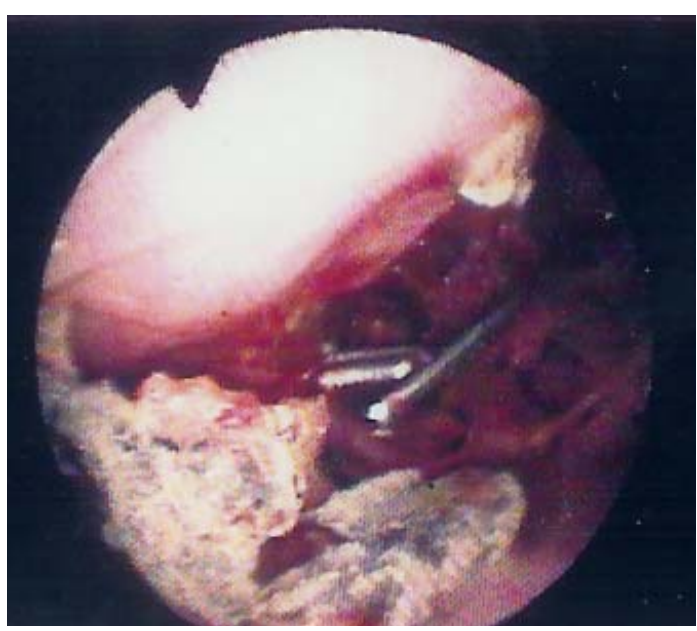

Figura 4. Imagem de lesão em placa, de etiologia fúngica, evidenciada ao exame endoscópico em eqüino.

Como durante o procedimento cirúrgico constatou-se que o aspecto externo e a aparência ao corte da massa não eram compatíveis com hematoma hetmoidal, o material ressecado foi corretamente encaminhado para exame histológico, que revelou lesão granulomatosa fúngica por Cryptococcus sp.

A criptococose acomete o homem e vários animais, podendo ocorrer em indivíduos imunocompetentes, mas freqüentemente está associada a um estado de comprometimento imunológico (Oliveira et al., 2005). Especificamente, em relação ao eqüino atendido, a infecção fúngica pode ter ocorrido após infecção viral ou bacteriana do trato respiratório superior, mas não se pode descartar um trauma decorrente de passagem de sonda nasogástrica ou até mesmo como seqüela da hemorragia pulmonar induzida por exercício (Begg et al., 2004). Num relato de criptococose em sete cavalos, seis tinham história de doenças que podem tê-los predisposto a criptococose (Riley et al., 1992).

É impossível determinar quando o cavalo foi infectado, mas tanto em animais como em humanos a criptococose resulta da inalação do fungo presente no meio ambiente e deposição no trato respiratório superior ou no alvéolo. Logo, é importante a investigação do potencial de exposição dos animais ou humanos a situações de risco de contrair a infecção, em ambientes possivelmente contaminados. O Cryptococcus sp. já foi isolado em locais urbanos com alta densidade de pessoas circulando, em ocos de árvores, ou seja, nichos de biodegradação natural da madeira, e em fezes secas de pombos e de outras aves (Oliveira, 2005; Kommers et al., 2005).

O eqüino acometido por criptococose pode vir a contaminar o meio ambiente, mas é questionável o quanto este animal oferece perigo para a saúde pública ou para outros animais, ou seja, não é evidente que a criptococose pode ser transmitida entre eqüinos, ou do eqüino para o homem (Roberts et al., 1981).

Scott et al. (1974) recomendaram o sacríficio de animais acometidos por criptococose devido à 
deficiência de medicamentos eficazes e a aspectos de saúde pública. Fato é que poucos eqüinos acometidos pela doença são tratados, pois a terapia é cara, longa, tem muitos efeitos colaterais e freqüentemente há recidivas (Chandna et al., 1992). Begg et al. (2004) citaram que o aquecimento de anfoterecina B entre 60 e $70^{\circ} \mathrm{C}$ por 10 minutos antes de sua administração aumenta a eficácia clínica contra a criptococose e diminui a nefrotoxicidade.

Como o tratamento com antifúngicos sistêmicos deve ser mantido por pelo menos três a quatro meses, demandando tempo e dinheiro (Chandna et al., 1992), e o resultado da ressecção cirúrgica pode ser muito satisfatório, optou-se pelo acompanhamento endoscópico da ferida até sua completa cicatrização, a fim de se observar possíveis recidivas.

Tremaine e Dixon (2001) relatam que infecções micóticas são observadas no pós- operatório de cirurgias nasais ou sinusais. De fato, três semanas após a ressecção cirúrgica foram observadas placas fúngicas por Aspergillus sp. no local da ferida. Como nos eqüinos hifas e esporos de Aspergillus sp. são encontrados comumente no trato respiratório de indivíduos normais (Greet, 1981; Guida et al., 2005), acredita-se que este agente comportou-se como um invasor secundário do tecido danificado pela ressecção cirúrgica.

A introdução de terapia por infusão de chá de camomila $(5 \mathrm{~g} / \mathrm{l})$ foi devido ao baixo custo, facilidade de obtenção do ingrediente e seu conhecido efeito antiinflamatório e antimicrobiano (Mckay e Blumberg, 2006), além de não possuir os efeitos colaterais dos antifúngicos sistêmicos. Deve ser salientado que as retiradas de placas fúngicas por meio endoscópico foram indispensáveis e contribuíram para o processo de cicatrização da mucosa.

Este caso ressalta a importância da utilização de métodos de coloração e técnicas laboratoriais não comumente utilizadas na rotina para a obtenção do diagnóstico. Apesar de não haver relatos sobre a utilização dos componentes da camomila (Matricaria recutita) em eqüinos, a lavagem com solução aquosa dessa planta pode ser benéfica na prevenção de infecções micóticas secundárias, ou mesmo como coadjuvante no tratamento cirúrgico de granulomas fúngicos.

\section{REFERÊNCIAS BIBLIOGRÁFICAS}

AINSWORTH, D.M.; BILLER, D.S. Sistema Respiratório. In: REED, S. M.; BAYLY, W. M. (Eds). Medicina interna eqüina. Rio de Janeiro: Ganabara Koogan, 2000. p.251-289.

BEGG, L.M.; HUGHES, K.J.; KESSELL, A. et al. Successful treatment of cryptococcal pneumonia in a pony mare. Aust. Vet. J., v.82, p.686-692, 2004.

BREARLEY, J. C.; McCANDLISH, I.A.P.; SULLIVAN, M. et al. Nasal granuloma caused by Pseudallescheria boydii. Equine Vet. J., v.18, p.151-153, 1986.

CHANDNA, V.K.; MORRIS, E.; GLIATTO, J.M. et al. Localised subcutaneous cryptococcal granuloma in a horse. Equine Vet. J., v.25, p.166-168, 1992.

DAVIS, P.R.; MEYER, G.A.; HANSON, R.R. et al. Pseudallescheria boydii infection of the nasal cavity of a horse. J. Am. Vet. Med. Assoc., v.217, p.707-709, 2000.

FREEMAN, D.E.; ORSINI, P.G.; ROSS, M.W. et al. A large frontonasal bone flap for sinus surgery in the horse. Vet. Surg., v.19, p.122-130, 1990.

FREEMAN D.E. Paranasal sinuses. In: BEECH, J. (Ed). Equine respiratory disorders. Pennsylvania: Lea \& Febiger, 1991. p.290-293.

GARDINER, P. Chamomille (Matricaria recutita, Anthemis nobilis). The longwood herbal task force, 1999. Disponível em: <http:// www.childrenshospital.org/holistic/>. Acessado em: 15 mar. 2006.

GIBBS, C.; LANE, J.G. Radiographic examination of the facial, nasal and paranasal sinus regions of the horse. II. Radiological findings. Equine Vet. J., v.19, p.474-482, 1987.

GRECO, F.B.; MARTINS, E.A.N.; RIBAS, J.A.S. et al. Rinosporidiose nasal em eqüinos pantaneiros no estado de Mato Grosso. In: ENCONTRO NACIONAL DE PATOLOGIA VETERINÁRIA, 11., 2003, Botucatu. Anais... Botucatu: [s.n.] 2003. p.193 (Resumo).

GREET T. R. Nasal aspergillosis in three horses. Vet. Rec., v.28, p.487-489, 1981.

GUIDA, N.; MESPLET, M.; DI GENNARO, E. et al. Aspergillus fumigatus in nasopharyngeal 
cavity of horses. Rev. Iberoam. Micol., v.22, p.160-162, 2005.

HUMBER, R.A.; BROWN, C.C.; KORNEGAV, R.W. Equine zygomycosis caused by Conidiobolus lamprauges. J. Clin. Microbiol., v.27, p.573-576, 1989.

KOMMERS, D.G.; SOUZA, T.M.; SOUTO, M.A.M. et al. Criptococose pulmonar granulomatosa em um eqüino. Cienc. Rural., v.35, p.938-940, 2005.

KORENEK, N.L.; LEGENDRE, A.M.; ANDREWS, F.M. et al. Treatment of mycotic rhinitis with itraconazole in three horses. J. Vet. Intern. Med., v.8, p.224-227, 1994.

LENARD, Z.M.; LESTER, N.V.; O'HARA, A.J. et al. Disseminated cryptococcosis including osteomyelitis in a horse. Aust. Vet. J., v.85, p.5155, 2007.

LONDERO, A.T.; SANTOS, M.N.; FREITAS, C.J.B. Animal rhinosporidiosis in Brazil. Report of three additional cases. Mycopathologia, v.60, p.171-173, 1977.

McGORUM, B.C.; DIXON, P.M.; LAWSON, G.H.K. A review of ten cases of mycotic rhinitis. Equine Vet. Educ., v.4, p.8-12, 1992.

McKAY, D.; BLUMBERG, J.B. A review of the bioactivity and potential health benefits of chamomile tea (Matricaria recutita L.). Phytother. Res., v.20, p.519-530, 2006.

OLIVEIRA, I.A.; NOBRE, M.O.; FERREIRO, L. Pesquisa de criptococose em cães atendidos no Hospital de Clínicas veterinárias da UFRGS, Porto Alegre, Brasil. Acta Sci. Vet., v.33, p.253258, 2005.

RAGLE, C.A. Guttural pouch disease. In: ROBINSON, N.E. (Ed). Current therapy in equine medicine. Philadelphia: Sauders, 2003. p.386-390.

REIS, A.M.S.; ABREU, A.N.; CAMIN, P.M.M. et al. Equine nasal rhinosporidiosis: case report in São Paulo, Brasil. In: CONGRESS OF THE INTERNATIONAL SOCIETY FOR HUMAN AND ANIMAL MYCOLOGY, 16., 2006, Paris. Anais...Paris: [s.n.] 2006. p.22. (Resumo).

RILEY, C.B.; BOLTON, J.R.; MILLS, J.N. et al. Cryptococcosis in seven horses. Aust. Vet. J., v.69, p.135-139, 1992.

ROBERTS, M.C.; SUTON, R.H.; LOVELL. D.K., Aprotracted case of cryptococcal nasal granuloma in a stallion. Aust. Vet. J., v.57, p.287291, 1981.

SANCHES, A. Avaliação citológica do lavado traqueobrônquico de eqüinos clinicamente sadios e daqueles portadores de afecções do sistema respiratório. 1998. 148f. Dissertação (Mestrado) - Faculdade de Medicina Veterinária e Zootecnia, Universidade de São Paulo, São Paulo.

SCOTT, E.A.; DUNCAN, J.R.; McCORMACK, J.E. Cryptococcosis involving the postorbital area and frontal sinus in a horse. J. Am. Vet. Med. Assoc., v.165, p.626-627, 1974.

TREMAINE, W.H.; DIXON, P.M. A long-term study of 277 cases of equine sinonasal disease. Part 1: Details of horses, historical, clinical and ancillary diagnostic findings. Equine Vet. J., v.33, p.274-282, 2001.

WATT, D.A. A case of cryptococcal granuloma in the nasal cavity of a horse. Aust. Vet. J., v.46, p.493-495, 1970.

ZAMOS, D.T.; SCHUMACHER, J.; LOV, J.K. Nasopharyngeal conidiobolomycosis in a horse. J. Am. Vet. Med. Assoc., v.208, p.100-101, 1996. 